\title{
Electroconvulsive Therapy in First Episode Schizophrenia - Experiences from Nepal
}

\author{
Adhikari SR
}

\author{
Associate Professor, Chitwan Medical College, Chitwan \\ Email Corresponding Author: shailendra_adhikary@hotmail.com
}

\begin{abstract}
Introduction: Little is known regarding efficacy and effectiveness of electroconvulsive therapy (ECT) in young, first episode schizophrenia. Present study was done to evaluate short term and long term efficacy and effectiveness of ECT in patients with first episode schizophrenia.

Materials and methods: This is a prospective study where forty five patients were evaluated at medical college in Nepal.12 patients received ECT as compared to 33 non-receivers. Patients were evaluated at admission, at discharge, 1st month, 6 th month and at 12 th month after discharge from the hospital. Evaluations were done using Brief Psychiatric Research Scale (BPRS), Global Assessment of Function (GAF).
\end{abstract}

Results: The mean duration of hospitalization was 25.42 days among ECT receivers as compared to 34.75 days among nonreceivers. Patients who received ECT showed significant improvement in BPRS at discharge $(p=0.001)$, 1 st month $(p=0.001,6$ th month $(p=0.001)$ and at 12 th month $(p=0.001)$. Similarly there was significant improvement in $G A F$ at discharge $(p=0.001)$, 6th month $(p=0.053)$ and at 12th month $(p=0.003)$.

Conclusion: Though used infrequently, ECT in young first episode schizophrenia give significant overall improvement and wellbeing with very minimal side-effects. ECT also shortens duration of hospitalization with early discharge and improvement in psychosocial wellbeing.

Keywords: ECT, schizophrenia, first episode, BPRS, GAF

\section{INTRODUCTION}

Over the past decade, schizophrenia has become more treatable than before, due to increased use of new generation of drug therapies. Progressive neuro-scientific advances will hold out strong possibilities of more definite biological treatments in near future. Despite this, historical importance of electroconvulsive therapy (ECT) continues in patients with schizophrenia. Though most reviewers conclude that the presence of depression is a factor predicting a positive effect of ECT in schizophrenia 1, many studies contradict these findings. Erwin \& Thompson ${ }^{2}$ believed that ECT does not treat the schizophrenic process but rather treats secondary mood disorders in schizophrenia. Wells ${ }^{3}$ examined records in a university hospital over 10 years and found that 76 percent of schizophrenia patients given ECT for the first time had moderate to severe depression and 54 percent had depression as the most prominent symptom. Patients with schizoaffective disorder and catatonia had the best response rate $(85 \%$ and $82 \%$, respectively). Despite these facts, ECT has been found to be very efficacious in schizophrenia, especially in first-break psychotic patients with excitement, over activity, florid delusion and severe hallucination which might create difficulties in initial management of patients. If patient is treated at the earliest course of illness especially who are young, the risk of chronicity, personality deterioration can be avoided and patient can be put in remission quite early ${ }^{4}$.

Most of the previous studies had focused on efficacy of ECT acute schizophrenia with catatonic 
subtype.5,6,7,8 ECT has also been used in chronic schizophrenia- also described as "last resort" in various literatures and in some cases treatment resistant schizophrenia (TRS). ${ }^{9,10,11,12,13,14,15}$ But we all know $30-50 \%$ of patients of schizophrenia have difficulties in initial psychotropic treatment ${ }^{16}$, with $10-15 \%$ developing treatment resistant even in the first episode. ${ }^{17,18}$ Considering long term debilitating condition of schizophrenia, it is important to intervene at the earliest stage of disease process since we have effective physical treatment in the form of ECT for nearly 70 years.

There are very few studies in the treatment of first episode schizophrenia (FES) by ECT with or without medications. But these studies are only cross-sectional with retrospective data analysis. Though Nepal has been using ECT for the last 40 years, no scientific research has been done so far. This will be the first study of its' kind that has been done in Nepal. In this study, outcome and efficacy of ECT was assessed in patients with first episode schizophrenia (FES).

\section{MATERIAL AND METHODS:}

Study Design- This was a naturalistic prospective study of patients who were admitted in the inpatient unit of medical college psychiatry department. Patients were assessed by qualified psychiatrists and diagnosis of schizophrenia was done as per ICD-10. ${ }^{19}$

Inclusion criteria: Patients and informants who were willing to participate in the study and gave consent. History had certain evidence that it was first episode schizophrenia (FES). Patients who had history of excitement /over activity / self-harm \& harm to others and extremely difficult to manage in wards despite adequate psychotropic drugs. Final decision to give ECT was decided by psychiatrists.

Exclusion criteria: Patients and informants who refused to give consent. Any evidences of past history of psychotic spectrum disorders and history of bipolar disorders. History of alcohol and substance abuse. Other general medical conditions that led to psychotic symptoms. No previous antipsychotic treatment and inpatient care.

Apart from informed consent from patients and relatives, ethical guidelines for biomedical research on human subjects by Nepal Health Research Council (NHRC) were also adhered to, in addition to principles enunciated in the "declaration of
Helsinki". Ethical approval from the "Institute Ethical Committee" of the medical college was also taken.

Sample consists of 45 patients with diagnosis of FES. Of them, 12 patients were given ECT (considered as ECT-receivers or ECT-R) and 33 patients did not receive ECT (considered as ECTnon-receivers or ECT-NR). They were assessed at the time of admission, at discharge, during first month / sixth month and at twelfth month of follow-up.

\section{Assessment:}

Demographic form: This form collected demographic variable- age, gender, educational level, marital status and occupation. Patient's psychopathology was assessed by administering Brief Psychiatric Research Scale (BPRS) ${ }^{20}$. Patient's day to day functional status was assessed by administering Global Assessment of Function $(\mathrm{GAF})^{21}$

ECT Technique: Pre-anesthetic assessment was necessary a day prior to procedure from the anesthesia department. ECT was done under general anesthesia using anesthetic agents such as Propofol $(2-5 \mathrm{mg} / \mathrm{kg})$ or Sodium Thiopentone (10$15 \mathrm{mg} / \mathrm{kg})$. Succinylcholine $(20-30 \mathrm{mg} / \mathrm{kg})$ was used as a muscle relaxant after above mentioned agents. Masked ventilation was also done using 100\% oxygen and vital signs were monitored along with ECG throughout the procedure. One of the arms was spared with B.P. cuff before administrating muscle relaxant so that adequate convulsing can be seen during ECT. At least 15 seconds of convulsion was considered as an effective convulsion though it varies from 10 seconds to 120 seconds depending upon the dose of anesthetic agents and clamping of BP cuff. Upward titration of electrical dose was done according to clinical improvement of the patients. Patients were shifted to post-operative ward after they become conscious, they were kept there for at least 2 hours and shifted to psychiatric ward.

ECT machine: The machine used for administering ECT was ECTON constant current and brief pulse ECT which has been manufactured by RMS, Chandigarh, India. This machine has of two types of operations - Brief Pulse Mode 1(PLS1); Brief Pulse Mode 2 (PLS2); The Sine Wave. Almost all of the procedure used in this study was done using PLS-1 to maintain uniformity in the procedure.

Concurrent medications: All patients were continued on the same antipsychotic drugs at the same dose when they underwent ECT. Non- 
antipsychotic drugs were limited to trihexyphenidyl for extra pyramidal symptoms, benzodiazepines for sleep / anxiety and other medications for nonspecific symptoms like body ache, headache. No other psychotropics other than mentioned above were used and no antidepressants were used. None of the patients in the study were on any long term medications for chronic medical illnesses. Patients who were not given ECT were also continued on the same medications as before and non-psychotic drugs were also limited as on ECT users.

Statistical Analysis: Statistical analysis was performed with SPSS program (version 12). Data interpretation was done along with mean, standard deviation. Tests for the statistical significance of the associations between the variables were also done.

\section{RESULT:}

There were 12 patients who received ECT (as ECT receivers / ECT-R) compared with 33 patients who did not received ECT (as non-receivers / ECTNR).These two groups of patients were compared in socio-demographic profile (age, gender, educational level, marital status and occupation) as shown in table 1.

Table 2 showed duration of hospitalization (DUH) and duration of illness (DUI). The mean DUH in ECT-receivers (ECT-R) was 25.42 days in ECT-nonreceivers (ECT-NR) was 34.75 days, there was decrement of nearly 9 days in ECT-R. The mean DUI was 206.88 days in ECT-R whereas it was 297.08 days in ECT-NR. Though it was first episode schizophrenia (FES) DUI in ECT-R was shorter as compare to ECT-NR, patients were given ECT due to reasons described above.

Table 3 showed psychopathological assessment using Brief Psychiatric Research Scale (BPRS) done at admission, discharge, $1^{\text {st }}$ month, $6^{\text {th }}$ month and at $12^{\text {th }}$ month in patients between non-receivers and receivers. As compared to ECT non-receivers, there were significant improvement in BPRS in ECT receivers at that time of discharge $(E C T-R=39.33$; $E C T-N R=48.21 ;$ TOTAL $=45.84 ; p=0.001), 1^{\text {st }}$ month (ECT-R=31.5; ECT-NR=38.76; TOTAL= 36.82; $\mathrm{p}=$ $0.001), 6^{\text {th }}$ month $(E C T-R=26.08 ; \quad E C T-N R=32.42$; TOTAL $=30.73 ; p=0.001)$ and at $1^{\text {st }}$ year $(E C T-$ $\mathrm{R}=22.58 ; \quad \mathrm{ECT}-\mathrm{NR}=26.48 ; \quad \mathrm{TOTAL}=25.44)$. Measurement decrements were more than $40-50 \%$ from the time of admission which as compared to ECT non-receivers were statistically significant.

Patient's day to day functional status was measured by Global Assessment of Function (GAF) (Table 4)

at admission, discharge and at $6^{\text {th }}$ month and at $12^{\text {th }}$ month. As compared to non-receivers, ECT receivers had significant improvement in GAF at discharge $\quad($ ECT-R=61.08; $\quad$ ECT-NR=53.33; TOTAL $=54.67 ; \mathrm{p}=0.001)$, at $6^{\text {th }}$ month $(E C T-R=73.75$; ECT-NR=67.42; TOTAL=69.11; TOTAL=0.053) and at $1^{\text {st }} \quad$ year $\quad(E C T-R=87.08 ; \quad E C T-R=79.64$; TOTAL $=81.62 ; p=0.003$ ). GAF measurement was improved by more than $50 \%$ in ECT receivers which were statistically significant. Measurement improvement was more than $40-50 \%$ from the time of admission which as compared to ECT nonreceivers were statistically significant.

Table 1: Socio-demographic profile of patients with First episode schizophrenia (FES)

\begin{tabular}{|c|c|c|c|}
\hline $\begin{array}{l}\text { Gender } \\
\\
\text { Male } \\
\text { Female }\end{array}$ & $\begin{array}{l}\text { ECT } \\
\text { Non- } \\
\text { receivers } \\
(\mathrm{N}=33) \\
22 \\
11\end{array}$ & $\begin{array}{l}\text { ECT } \\
\text { Receivers } \\
(\mathrm{N}=12) \\
11 \\
1\end{array}$ & $\begin{array}{l}\text { TOTAL } \\
33 \\
12\end{array}$ \\
\hline $\begin{array}{l}\text { Age } \\
<20 \text { years } \\
20-29 \text { years } \\
30-39 \text { years } \\
>40 \text { years }\end{array}$ & $\begin{array}{l}2 \\
22 \\
7 \\
2\end{array}$ & $\begin{array}{l}1 \\
9 \\
2 \\
0\end{array}$ & $\begin{array}{l}3 \\
31 \\
9 \\
2\end{array}$ \\
\hline $\begin{array}{l}\text { Marital } \\
\text { Status } \\
\text { Married } \\
\text { Unmarried }\end{array}$ & $\begin{array}{l}14 \\
19\end{array}$ & $\begin{array}{l}5 \\
7\end{array}$ & $\begin{array}{l}19 \\
26\end{array}$ \\
\hline $\begin{array}{l}\text { Education } \\
\text { Illiterate } \\
\text { Primary } \\
\text { Middle } \\
\text { High School } \\
\text { Intermediate } \\
\text { Graduate } \\
\text { Post graduate }\end{array}$ & $\begin{array}{l}2 \\
3 \\
6 \\
9 \\
5 \\
3 \\
5\end{array}$ & $\begin{array}{l}0 \\
0 \\
3 \\
4 \\
4 \\
0 \\
1\end{array}$ & $\begin{array}{l}2 \\
3 \\
9 \\
13 \\
9 \\
3 \\
6\end{array}$ \\
\hline $\begin{array}{l}\text { Occupation } \\
\text { Business } \\
\text { Farmer } \\
\text { Labor } \\
\text { Service } \\
\text { Student } \\
\text { House wife } \\
\text { Unemployed } \\
\text { Others }\end{array}$ & $\begin{array}{l}1 \\
5 \\
6 \\
3 \\
7 \\
3 \\
7 \\
1\end{array}$ & $\begin{array}{l}0 \\
2 \\
2 \\
0 \\
3 \\
1 \\
3 \\
1\end{array}$ & $\begin{array}{l}1 \\
7 \\
8 \\
3 \\
10 \\
4 \\
10 \\
2\end{array}$ \\
\hline
\end{tabular}


TABLE 2 Comparing duration of hospitalization (DUH) and duration of illness (DUI) between ECT nonreceivers vs. receivers in patients with FES

\begin{tabular}{|l|l|l|}
\hline $\begin{array}{l}\text { Duration of hospitalization } \\
(\mathrm{DUH}) \text { (in days) }\end{array}$ & $\begin{array}{l}\text { ECT non-receivers } \\
(\mathrm{N}=33)\end{array}$ & $\begin{array}{l}\text { ECT receivers } \\
(\mathrm{N}=12)\end{array}$ \\
Mean $=25.42$ \\
\hline $\begin{array}{l}\text { Duration of illness } \\
(\mathrm{DUI}) \text { (in days) }\end{array}$ & Mean=297.08 & Mean=206.88 \\
\hline
\end{tabular}

Table 3: Comparing Brief Psychiatric Research Scale (BPRS) between ECT non-receivers and receivers with FES at admission, discharge and follow-up at 1st month, 6th month and 12th month

\begin{tabular}{|c|c|c|c|c|c|c|}
\hline $\begin{array}{l}\text { ECT non-receivers } \\
(\mathrm{N}=33)\end{array}$ & $\begin{array}{l}\text { Mean= } \\
\text { S.D. = }\end{array}$ & $\begin{array}{l}\text { Admission } \\
79.85 \\
8.109\end{array}$ & $\begin{array}{l}\text { Discharge } \\
48.21 \\
4.278\end{array}$ & $\begin{array}{l}1^{\text {st }} \text { month } \\
38.76 \\
3.857\end{array}$ & $\begin{array}{l}6^{\text {th }} \text { month } \\
32.42 \\
3.623\end{array}$ & $\begin{array}{l}1^{\text {styear }} \\
26.48 \\
3.043\end{array}$ \\
\hline $\begin{array}{l}\text { ECT receivers } \\
(\mathrm{N}=12)\end{array}$ & $\begin{array}{l}\text { Mean= } \\
\text { S.D. = }\end{array}$ & $\begin{array}{l}84.50 \\
7.598 \\
\end{array}$ & $\begin{array}{l}39.33 \\
4.942 \\
\end{array}$ & $\begin{array}{l}31.50 \\
5.519 \\
\end{array}$ & $\begin{array}{l}26.08 \\
4.078 \\
\end{array}$ & $\begin{array}{l}22.58 \\
2.466 \\
\end{array}$ \\
\hline TOTAL $=45$ & $\begin{array}{l}\text { Mean }= \\
\text { S.D. }=\end{array}$ & $\begin{array}{l}81.09 \\
8.160\end{array}$ & $\begin{array}{l}45.84 \\
5.931\end{array}$ & $\begin{array}{l}36.82 \\
5.382\end{array}$ & $\begin{array}{l}30.73 \\
4.663\end{array}$ & $\begin{array}{l}25.44 \\
33.61\end{array}$ \\
\hline $\begin{array}{l}\text { Statistical significance } \\
\text { ( } p \text { value) }\end{array}$ & & 0.091 & 0.001 & 0.001 & 0.001 & 0.001 \\
\hline
\end{tabular}

TABLE 4 Comparing Global Assessment of Function (GAF) between ECT non-receivers and receivers with FES at admission, discharge and follow-up $6^{\text {th }}$ month and $12^{\text {th }}$ month

\begin{tabular}{|c|c|c|c|c|c|}
\hline $\begin{array}{l}\text { ECT non-receivers } \\
(\mathrm{N}=33)\end{array}$ & $\begin{array}{l}\text { Mean= } \\
\text { S.D. = }\end{array}$ & $\begin{array}{l}\text { Admission } \\
17.88 \\
4.285\end{array}$ & $\begin{array}{l}\text { Discharge } \\
52.33 \\
6.436\end{array}$ & $\begin{array}{l}6^{\text {th }} \text { month } \\
67.42 \\
6.124\end{array}$ & $\begin{array}{l}1^{\text {st }} \text { year } \\
79.64 \\
7.420\end{array}$ \\
\hline $\begin{array}{l}\text { ECT receivers } \\
(\mathrm{N}=12)\end{array}$ & $\begin{array}{l}\text { Mean= } \\
\text { S.D. = }\end{array}$ & $\begin{array}{l}11.08 \\
5.160 \\
\end{array}$ & $\begin{array}{l}61.08 \\
7.166 \\
\end{array}$ & $\begin{array}{l}73.75 \\
5.481 \\
\end{array}$ & $\begin{array}{l}87.08 \\
5.035\end{array}$ \\
\hline TOTAL $=45$ & $\begin{array}{l}\text { Mean= } \\
\text { S.D. = }\end{array}$ & $\begin{array}{l}16.07 \\
5.408\end{array}$ & $\begin{array}{l}54.67 \\
7.634\end{array}$ & $\begin{array}{l}69.11 \\
9.757\end{array}$ & $\begin{array}{l}81.62 \\
7.581\end{array}$ \\
\hline $\begin{array}{l}\text { Statistical significance } \\
\text { ( } p \text { value) }\end{array}$ & & 0.001 & 0.001 & 0.053 & 0.003 \\
\hline
\end{tabular}

\section{DISCUSSION:}

We believe this study is the first of its kind done in Nepal where ECT is infamously known in Nepal as "Bijuli ko Jhadka" or "Electric Shock" and carries misconception not only among lay people but also among medical professionals and media, which further contributes to negative stigmatization ${ }^{22}$. This leads to great resistance from patients and their family members. Thus ECT in Nepal is an important effective treatment but most of the time underutilized and often ignored. All first episode schizophrenia (FES) patients who received ECT in this study showed significant improvement in psychopathology and day to day functioning. Their quality of life improved, with great reduction in requirement of psychotropic drugs. The one year follow-up was achievable in all the patients who 
underwent ECT. Patients were in follow-up further than our study period of 12 months.

This study is unique in a way that ECT was used FES as various literature considers ECT only in affective psychopathology. In acutely violent and agitated patients or patients showing disorganized and excited behavior, it would be extremely difficult and problematic to keep patients only on psychotropic drugs for 6-8 weeks as recommended by guidelines. Side effects of drugs and longer duration of hospitalizations also has to be considered. These are the reasons why ECT was considered in FES in this study. As shown in other studies in FES23, 24. Most of the patients in this study had diagnosis of catatonic, paranoid, and undifferentiated schizophrenia (table5). Though it is well known from study that ECT is effective in catatonic subtype ${ }^{25}, 26,27,28$, this study also showed effectiveness of ECT in paranoid and disorganized subtype.

There are few limitations of this study: (1) it is an open label study. (2) Psychotropic drugs and their doses were altered according to clinical judgment. (3) As ECT is not considered first line treatment in FES in most of the treatment protocol, this study had restricted indications for ECT leading to less number of ECT receivers than non-receivers. This will have difficulties in generalizing our findings in patients with FES.

Historically, ECT has been poorly studied because of various reasons, like stigma and prejudice attached to the treatment, including technical drawbacks in the designs of the studies or general ambivalence in the medical and research community towards its use ${ }^{29}$. Though there is negative attitude in the community regarding its use, our study showed ECT to be highly efficacious treatment even in severe mental illness, like FES.

\section{ACKNOWLEDGEMENT:}

I did not receive any kind of funds to conduct this study. I like to thank all the staffs of psychiatry inpatient unit and operation theatre for helping me conduct this research. I also like to acknowledge Kathmandu Medical College Teaching Hospital (KMCTH), Sinamangal-33, and Kathmandu, Nepal for giving me opportunity to conduct this project.

\section{CONCLUSION:}

Though used infrequently, ECT in young first episode schizophrenia give significant overall improvement and wellbeing with very minimal side-effects. ECT also shortens duration of hospitalization with early discharge and improvement in psychosocial wellbeing.

\section{REFERENCES:}

1. Celeste A, Johns and James W. Thompson. Adjunctive Treatments in Schizophrenia: Pharmacotherapies and Electroconvulsive Therapy. Schizophrenia Bulletin 1995; 21(4): 607-619.

2. Erwin CW and Thompson EM. ECT in schizophrenia: $A$ study in nosologic imprecision. In: Brady, JP and Brodie HKH eds. Controversy in Psychiatry. Philadelphia, PA: W.B. Saunders \& Company, 1978. pp. 165-182.

3. Wells, DA. ECT for schizophrenia: A ten-year survey in a university hospital psychiatric department. Comprehensive Psychiatry 1973; 14: 291-298.

4. Fink M, Sackeim HA. Convulsive therapy in schizophrenia. Schizophrenia Bulletin 1996; 22: 27-39.

5. Hayashi H, Aoshima T, Otani K. Malignant catatonia with severe bronchorrhea and its response to electroconvulsive

Therapy. Prog Neuropsychopharmacol Biol Psychiatry 2006; 30(2):310-311.

6. Suzuki K, Awata S, Takano T, Ebina Y, Shindo T, Harada $N$, et al. Adjusting the frequency of continuation and maintenance electroconvulsive therapy to prevent relapse of catatonic schizophrenia in middle aged and elderly patients who are relapse-prone. Psychiatry Clin Neurosci 2006; 60(4):486492.

7. Suzuki K, Shindo T, Katsura M, Takamatsu K, Ebina Y, Takano $T$, et al. Resolution of catatonia by successful seizure induction via electroconvulsive therapy with electrodes applied bilaterally to the parietotemporal region. J ECT 2007; 23(2):103- 105.

8. Swoboda E, Conca A, König P, Waahders R, Hansen $M$ (2001) Maintenance electroconvulsive therapy in affective and schizoaffective disorder. Neuropsychobiology 2001; 43(1):2328.

9. Schott K, Bartels M, Heimann H, Buchkremer G. Results of electroconvulsive therapy in restrictive indications. A retrospective study of 15 years. Nervenarzt 1992; 63(7):422425 .

10. Kales HC, Dequardo JR, Tandon $R$. Combined electroconvulsive therapy and clozapine in treatment-resistant schizophrenia. Prog Neuropsychopharmacol Biol Psychiatry 1999; 23(3):547-556.

11. Tang WK, Ungvari. Efficacy of ECT combined with antipsychotic medication in TRS: A prospective open trial. J ECT 2002; 18: 90 - 94.

12. Tang WK, Ungvari GS. Efficacy of ECT in TRS: A prospective open trial. Prog Neuropsychopharmacol Biol Psychiatry 2003; 27: 373 - 379.

13. Braga RJ, Petrides G.The combined use of electroconvulsive therapy and antipsychotics in patients with schizophrenia. J ECT 2005; 21:75-83.

14. Havaki-Kontaxaki BJ, Ferentinos PP, Kontaxakis VP, Paplos KG, Soldatos CR. Concurrent administration of clozapine and electroconvulsive therapy in clozapine resistant schizophrenia. Clin Neuropharmacol 2006; 29(1):52-56.

15. Garg R, Chavan BS, Arun P. Short-Term efficacy of electroconvulsive therapy in treatment-resistant schizophrenia. German J Psychiatry 2012; 15(2):44-49. 
16. Chanpattana $W$, Andrade C. ECT for treatment-resistant schizophrenia: A response from the Far East to the UK. NICE Report. J ECT 2006; 22: 4-12.

17. Barnes TR, Hutton SB, Chapman MJ et al. West London first-episode study of schizophrenia. Clinical correlates of duration of untreated psychosis. British J Psychiatry 2000; 177:207-211.

18. Lieberman JA, Phillips $M, G u H$ et al. Atypical and conventional antipsychotic drugs in treatment-naïve firstepisode schizophrenia: a 52-week randomized trial of clozapine $v$ chlorpromazine. Neuropsychopharmacology 2003; 28:9951003.

19. World Health Organization (WHO). The ICD - 10 classifications of mental and behavioral disorders: Diagnostic criteria for research 1992, Geneva: World Health Organization. 20. Lukoff D, Nuechterlein KH, Ventura J. Manual for the Expanded Brief Psychiatric Rating Scale (BPRS). Schizophrenia Bull1986; 12:594-602.

21. Endicott J, Spitzer RL, Fleiss JL, Cohen J. The Global Assessment Scale: A procedure for measuring overall severity of psychiatric disturbance. Arch Gen Psychiatry 1976; 33:766.

22. McDonald A, Walter G. The Portrayal of ECT in American Movies. J ECT 2001; 17:264-74.

23. Das PS, Saxena S, Mohan D, et al. Adjunctive electroconvulsive therapy for schizophrenia. Natl Med J India 1991; 4:183-184.

24. Ucok A, Cakir S. Electroconvulsive therapy in first episode schizophrenia. J ECT 2006; 22:38-42.

25. Rey JM, Walter G. Half a century of ECT use in young people. Am J Psychiatry 1997; 154:595-602.

26. Cohen D, Dubos PF, Basquin M. Use of electroconvulsive therapy in the adolescent. Encephale 1997; 23:308-311.

27. Ucok A, Ucok G. Maintenance ECT in a patient with catatonic schizophrenia and tardive dyskinesia. Convuls Therapy 1996; 12:108-112.

28. Stein D, Kurtsman L, Stier $S$, et al. Electroconvulsive therapy in adolescent and adult psychiatric inpatients- a retrospective chart design. J Affect. Disorder 2004; 1(82):335342.

29. Salzman C. ECT, research and professional ambivalence. Am J Psychiatry 1998; 155:1-2. 